\title{
Interfacial interactions in PTT-PTMO/polyhedral oligomeric silsesquioxane (POSS) nanocomposites and their impact on mechanical, thermal, and dielectric properties
}

\author{
Sandra Paszkiewicz ${ }^{1}$ - Daria Pawlikowska ${ }^{1}$ - Anna Szymczyk ${ }^{2}$ (D) \\ Beata Dudziec $^{3} \cdot$ Michal Dutkiewicz $^{4} \cdot$ Bogdan Marciniec $^{4}$ (D) \\ Amelia Linares ${ }^{5}$ (D) Tiberio A. Ezquerra ${ }^{5}$ (D)
}

Received: 16 September 2017/Revised: 12 January 2018/Accepted: 13 March 2018/ Published online: 16 March 2018

(C) The Author(s) 2018

\begin{abstract}
Poly(trimethylene terephthalate-block-tetramethylene oxide) (PTTPTMO)/polyhedral oligomeric silsesquioxane (POSS) nanocomposites, synthesized by in situ polymerization, are characterized in detail in terms of interfacial interactions between functional groups on the surface of POSS and polymer chains. The impact of POSS incorporation on the molecular mobility is investigated by means of dielectric spectroscopy. It is found that PTT-PTMO/POSS nanocomposites exhibit higher values of stress at strain of $100 \%$ that in comparison with neat PTT-PTMO might result from the influence of POSS particles on the molecular mobility of polymer chains, which is probably due to the interfacial interactions between functional groups on the surface of POSS particles with the polymer matrix. Moreover, it is found that there is no variation of the segmental relaxation for the nanocomposite investigated and there is an increase in the interfacial polarization induced by the presence of POSS as seen in the increment of the real part of the dielectric permittivity.
\end{abstract}

Sandra Paszkiewicz

spaszkiewicz@zut.edu.pl

1 Institute of Materials Science and Engineering, Faculty of Mechanical Engineering and Mechatronics, West Pomeranian University of Technology, Piastów Av. 17, 70-310 Szczecin, Poland

2 Institute of Physics, Faculty of Mechanical Engineering and Mechatronics, West Pomeranian University of Technology, Piastów Av. 48, 70-311 Szczecin, Poland

3 Department of Organometallic Chemistry, Faculty of Chemistry, Adam Mickiewicz University in Poznan, Umultowska 89B, 61-614 Poznan, Poland

4 Center for Advanced Technologies, Adam Mickiewicz University in Poznan, Umultowska 89C, 61-614 Poznan, Poland

5 Instituto de Estructura de la Materia, IEM-CSIC, Serrano 121, 28006 Madrid, Spain 
Keywords POSS nanoparticles · Thermoplastic elastomers · Interfacial interactions · In situ polymerization - Thermal stability · Mechanical properties · Dielectric properties

\section{Introduction}

Polyhedral oligomeric silsesquioxane (POSS) is a nanostructured chemical that bridges the gap between ceramic and organic materials, since it consists of both organic and inorganic matter with an inner core of inorganic silicon and oxygen and an outer layer of organic constituents, which could be either polar or nonpolar [1]. POSS technology is derived from a continually evolving class of compounds closely related to silicones through both composition and a shared system of nomenclature. POSS chemical technology has two unique features; first of all, the chemical composition is a hybrid, intermediate $\left(\mathrm{RSiO}_{1.5}\right)$ between that of silica $\left(\mathrm{SiO}_{2}\right)$ and silicone $\left(\mathrm{R}_{2} \mathrm{SiO}\right)$, where $\mathrm{R}$ may be a hydrogen atom or an organic functional group, e.g., alkyl, alkylene, acrylate, hydroxyl, or epoxide unit [2-5]. In addition, second, POSS molecules are physically large with respect to polymer dimensions and nearly equivalent in size to most polymer segments and coils. POSS chemical technology is easy to use and available in both liquid and solid form. POSS nanostructures exhibit diameters in the range 1-3 $\mathrm{nm}$ and, hence, may be considered as the smallest existing silica particles [2]. However, unlike silica or modified clays, each POSS molecule contains covalently bonded reactive functionalities suitable for polymerization or grafting POSS monomers to polymer chains. Each POSS molecule contains nonreactive organic functionalities for solubility and compatibility of the POSS segments with the various polymer systems. One classified POSS particles as having a zero-dimensionality; however, the ability to create higher dimensionality $(1,2$, or $3 \mathrm{D}$ scaffolds) through aggregation or crystallization of the POSS particles within the polymer matrix has been reported [6]. This chemical diversity of POSS technology is very broad and a large number of POSS monomers and polymers are currently available and under development. Enhancements in the physical properties of nanocomposites containing POSS segments result from POSS's ability to control the motions of the chains while still maintaining the processability and mechanical properties of the base resin. This is a direct result of POSS's nanoscopic size and its relationship to polymer dimensions. Nonetheless, POSS improves product performance (reduces the flammability, heat discharge, and viscosity of the polymer [7-10]) while retaining its lightweight and ductile features, without sacrificing mechanical properties (may cause an increase of strength, modulus, rigidity) and is used in a wide variety of applications, e.g., drug delivery, polymer electrolytes, thermoplastic, and thermosetting polymers [11-14]. However, the properties of polymer nanocomposites containing POSS nanostructures depend on the successful incorporation of POSS particles in polymer matrices. Thus, two approaches have been adopted to incorporate POSS particles into polymer matrices: (1) chemical cross-linking [2, 15] and (2) physical blending [1]. First approach depends on the covalent bonding between POSS nanoparticles and polymer matrix. Whereas, in the 
second approach, POSS nanoparticles are physically blended with polymer by melt mixing or solvent casting methods. The cause of success of physical blending lies in the compatibility of POSS particles with the polymers [1, 16, 17]. Interfacial interactions between POSS nanostructures and polymer matrix are mediated by ligands, which are attached to the nanoparticles, and hence, ligands play a key role in affecting the particle behavior and spatial distribution [18]. One can achieve the surface functionalization of nanoparticles by attaching small functional molecules and polymers either covalently [18] or by physical adsorption [19, 20]. However, there are still a number of key challenges encountered in preparing polymer nanocomposites containing POSS particles, some of which include long-range equilibration time, aggregation of nanoparticles, and expensive large-scale production [18, 21]. Moreover, the control of location and nanostructure of nanoparticles in polymer nanocomposites remain open challenges. As a result, two processing technique shave been developed to incorporate nanoparticles into polymer matrices either by in situ polymerization or by physical blending (e.g., melt mixing) [1].

Thermoplastic elastomers (TPEs) are the multi-phase polymer materials or polymer blends that in the wide range of temperatures exhibit properties characteristic for rubber. Due to their flexibility, one can stretch them repeatedly at room temperature to at least double of their original length and then to return to their approximate original length when stress is released. TPEs can be obtained by copolymerizing two or more monomers, using either block or graft polymerization techniques [22]. Structural differences of monomers usually cause separation of flexible (a continuous soft phase with a low glass transition temperature) and rigid (a dispersed hard phase with a high melting temperature) segments into two phases (domains) [22, 23]. One of the monomers provides hard, or crystalline, polymer segment that works as a thermally stable component, whereas the other monomer forms the soft, or amorphous segment, which contributes the elastomeric or rubbery characteristic [22]. Properties of these materials can be controlled by varying the ratio of the monomers and the length of the hard and soft segments. The way how these materials are prepared is of great importance, since block techniques create long-chain molecules that have various or alternating hard and soft segments while the graft polymerization methods involve attaching one polymer chain to another as a branch [22]. The best example of a thermoplastic polyester elastomer is Hytrel ${ }^{\circledR}$ made by DuPont. Hytrel ${ }^{\circledR}$ offers a unique combination of mechanical, physical and chemical properties that qualifies it for demanding applications. This type of material is used in a wide ranges of applications include seals, belts, bushings, gears, protective boots, hose, and springs [24]. Moreover, TPEs have been widely used for various applications in automotive parts, electrical and medical industries and packaging because of their outstanding endurance, low density and relatively low manufacturing cost [25]. Notwithstanding, TPEs materials can be based on different polyesters and polyethers. The example of that kind of materials is multiblock poly(ether-ester) (PEE) based on poly(butylene terephthalate) (PBT) as rigid segments and poly(tetramethylene oxide) (PTMO) as flexible ones [26, 27]. In the last several years, a family of thermoplastic polyester elastomers based on poly(trimethylene terephthalate), i.e., poly(trimethylene terephthalate-block-tetramethylene oxide) (PTT-PTMO), has been studied [28]. This material exhibits 
excellent thermoplastic elastomer properties, such as a low glass transition temperature, high melting point, and a temperature-independent rubbery plateau [28]. However, more recently, it was found that the properties of PTT-PTMO can be further improved by the addition of either inorganic particles like montmorillonite (MMT) [29], POSS [23], silicon carbide nanofibers (SiC) [30] or organic nanofillers such as single-walled carbon nanotubes (SWCNT) [31], graphene oxide [32] or even a hybrid system of nanofillers like SWCNT and graphene nanoplatelets (GNP) [33, 34]. However, it was found that at the same concentration, carbon nanofillers (like SWCNT or GNP) affect the polymer matrix in stronger manner [35].

This work is a continuation of the study on the new thermoplastic elastomers based on PTT-PTMO containing POSS nanoparticles prepared by in situ polymerization for improved mechanical and thermal properties. In addition, the neat PTTPTMO copolymer and the PTT-PTMO-based nanocomposite with the highest content of POSS nanoparticles, i.e., $1.0 \mathrm{wt} \%$, have been analyzed by dielectric spectroscopy to estimate the influence of POSS particles on the morphology of the polymer matrix.

\section{Experimental section}

\section{Materials}

Nanocomposites were synthesized by melt transesterification and subsequently polycondensation as follows according to the procedure described previously in [23]. The following substrates were used to prepare the nanocomposites: dimethyl terephthalate (DMT, Sigma-Aldrich), poly(tetramethylene oxide) glycol with molecular weight of $1000 \mathrm{~g} / \mathrm{mol}$ (PTMG, Terathane 1000, DuPont, USA), 1,3propanediol (PDO, Susterra ${ }^{\circledR}$ Propanediol, DuPont Tate\&Lyle, USA), tetrabutyl orthotitanate (TBT, Fluka) as the catalyst in transesterification and polycondensation and Irganox 1010 (Ciba-Geigy, Switzerland) as thermal antioxidant. In brief, the transesterification reaction between DMT and PDO (or the mixture of POSS/ PDO in the case of nanocomposites) was carried out under a constant flow of nitrogen at temperature of $160-190{ }^{\circ} \mathrm{C}$ for ca. $2.5 \mathrm{~h}$ in the presence of first portion of catalyst. During this step, methanol was distilled and collected as a by-product. The conversion of the transesterification reaction was calculated by monitoring the amount of effluent by-product. When the distillation of methanol has been ceasing, the reaction was completed and the temperature was gradually increased to up $220{ }^{\circ} \mathrm{C}$. Then, the PTMG and thermal antioxidant along with the second catalyst were introduced to the reactor. The reaction temperature was increased up to $250{ }^{\circ} \mathrm{C}$. Vacuum was applied gradually and the final pressure was lower than $25 \mathrm{~Pa}$. The stirring torque change was monitored to estimate the melt viscosity of the product at temperature of $250{ }^{\circ} \mathrm{C}$. The process was found to be finished when the reaction mixture reached the same value of melt viscosity, which was estimated by monitoring the stirring torque. POSS particles were provided by Center for Advanced Technologies obtained according to a sequential methodology presented 
in [23, 36-39] and with the size published already in [40]. The obtained nanocomposites were based on the block copolymer containing $50 \mathrm{wt} \%$ of PTT rigid segments and $50 \mathrm{wt} \%$ of PTMO flexible segments.

\section{Sample preparation}

The dumbbell-shaped samples (ISO 37 modified type 3 with enlarged gripping part) for tensile tests were obtained using a Boy 15 (Dr BOY GmbH\&Co., Germany) injection moulding machine with the following parameters: injection pressure $55 \mathrm{MPa}$, melt temperature $225{ }^{\circ} \mathrm{C}$, mould temperature $30{ }^{\circ} \mathrm{C}$, holding down pressure of $20 \mathrm{MPa}$ for $15 \mathrm{~s}$, and cooling time $10 \mathrm{~s}$. Films for dielectric spectroscopy measurements with thickness of about $200 \mu \mathrm{m}$ were obtained by compression moulding in a press at $230{ }^{\circ} \mathrm{C}$ for 2 min using the pressure of $5 \mathrm{MPa}$ and $2 \mathrm{~min}$ at $10 \mathrm{MPa}$ and then cooled down at room temperature with running water.

\section{Characterization techniques}

The intrinsic viscosity $[\eta]$ of the samples was determined at $30{ }^{\circ} \mathrm{C}$ in the mixture of phenol/1, 1,2,2-tetrachloroethane ( $60 / 40$ by weight). The polymer solution had a concentration of $0.5 \mathrm{~g} / \mathrm{dl}$. The measurement was carried using a capillary Ubbelohde viscometer (type Ic, $K=0.03294$ ).

Hardness measurements were performed on a Shore D apparatus (Karl Frank GmbH, Type 104, Germany) according to a standard DIN 53505 and ISO 868.

Tensile measurements were carried out on Instron 5566 universal tensile testing frame, equipped with a $5 \mathrm{kN}$ Instron load cell, a contact optical long travel extensometer, and the Bluehill 2 software. The measurements were performed at room temperature using a cross-head speed of $100 \mathrm{~mm} / \mathrm{min}$ and a grip distance of $20 \mathrm{~mm}$. The tensile modulus, stress at $100 \%$ strain, yield stress and strain, stress, and elongation at break of the nanocomposites were determined. Five measurements were conducted for each sample, and the results were averaged to obtain a mean value.

Thermo-oxidative and thermal stability of the in situ synthesized PTT-PTMObased nanocomposites containing POSS particles were evaluated by thermogravimetry (TGA 92-16.18 Setaram) using the system measuring simultaneously TG-DSC. Measurements were carried out in an oxidizing atmosphere, i.e., dry, synthetic air $\left(\mathrm{N}_{2}: \mathrm{O}_{2}=80: 20 \mathrm{vol} \%\right)$, and in an inert atmosphere (argon). The study was conducted at a heating rate of $10{ }^{\circ} \mathrm{C} / \mathrm{min}$ in the temperature range of 20-700 ${ }^{\circ} \mathrm{C}$. Measurements were conducted in accordance with the PN-EN ISO 11358:2004 standard.

The measurements of the complex dielectric permittivity $\varepsilon^{*}(\omega)=\varepsilon^{\prime}(\omega)-\varepsilon^{\prime \prime}(\omega)$ (where $\omega$ is angular frequency and $\varepsilon^{\prime}$ represents the permittivity and $\varepsilon^{\prime \prime}$ the dielectric loss) were conducted using of a Novocontrol broadband dielectric spectrometer in the frequency range from $10^{-1}$ to $10^{6} \mathrm{~Hz}$ and temperature range from -150 to $100{ }^{\circ} \mathrm{C}$. During the measurement, the temperature control was executed by a Quatro System (Novocontrol) using a jet of dry nitrogen, thereby ensuring temperature 
error of $0.1{ }^{\circ} \mathrm{C}$ during every single sweep in frequency. Sample films with circular gold electrodes ( $2 \mathrm{~cm}$ in diameter) deposited onto their surface were sandwiched between the two metallic electrodes of the spectrometer.

\section{Results and discussion}

\section{Physical properties of nanocomposites}

In Table 1, the characteristic properties of the obtained nanocomposites are summarized. As the content of POSS increases, the nanocomposites have higher values of the limiting viscosity number $([\eta])$ than neat PTT-PTMO block copolymer. Furthermore, all nanocomposites containing more than $0.5 \mathrm{wt} \%$ of POSS exhibit slight increase of hardness, which result probably from the changes in the multi-phase structure in the obtained nanocomposites The morphology of the block copolymers, which constitute the matrix in nanocomposites, is consisted of semicrystalline PTT domains dispersed in the soft phase of amorphous, noncrystallisable PTMO [28]. The nanometric structure of segregated rigid and soft segments is mainly responsible for the mechanical properties of these block copolymers. The representative stress-strain curves are presented in Fig. 1. The values of stress at strain of $100 \%(\sigma(100 \%))$ (Table 2$)$ increase with the content of POSS particles. The stress at yield $\left(\sigma_{\mathrm{y}}\right)$ also increases along with an increase in POSS concentration and achieves the highest value of $13.6 \mathrm{MPa}$ for PTT-PTMO/ 1.OPOSS nanocomposite. The values of strain at yield $\left(\varepsilon_{\mathrm{y}}\right)$ are higher in comparison with neat PTT-PTMO, but in this case, the highest value was observed for nanocomposite with $0.3 \mathrm{wt} \%$ of POSS particles (improvement of about $30 \%$ ). In turn, the values of stress at break $\left(\sigma_{\mathrm{b}}\right)$ increase initially up to the concentration of $0.5 \mathrm{wt} \%$ of POSS and equals $29.9 \mathrm{MPa}$, and then decrease. In this case, also the highest value was observed for the nanocomposite that contains $0.3 \mathrm{wt} \%$ of POSS particles. Since the degrees of crystallinity for the whole series of nanocomposites (Table 1) are comparable to one another, and especially to the neat PTT-PTMO, the improvement in the tensile properties is most likely the result of additional physical network nodes that through interfacial interactions between the matrix and POSS

Table 1 Characteristics of PTT-PTMO/POSS nanocomposites

\begin{tabular}{llllll}
\hline Sample & {$[\eta](\mathrm{dl} / \mathrm{g})$} & $H($ Shore D) & $T_{\mathrm{g}}[23]\left({ }^{\circ} \mathrm{C}\right)$ & $T_{\mathrm{m}}[23]\left({ }^{\circ} \mathrm{C}\right)$ & $x_{\mathrm{c}}[23](\%)$ \\
\hline PTT-PTMO & 1.392 & 41 & -68 & 205 & 24.1 \\
PTT-PTMO/0.1 POSS & 1.387 & 41 & -67 & 203 & 23.1 \\
PTT-PTMO/0.3 POSS & 1.451 & 41 & -68 & 204 & 24.6 \\
PTT-PTMO/0.5 POSS & 1.523 & 43 & -68 & 204 & 25.4 \\
PTT-PTMO/1.0 POSS & 1.539 & 43 & -68 & 207 & 24.1 \\
\hline
\end{tabular}

[ $\eta$ ] intrinsic viscosity, $H$ hardness, $T_{g}$ glass transition temperature of soft phase, $T_{m}$ melting temperature of polyester crystalline phase, $x_{c}$ degree of crystallinity determined by DSC [23] 


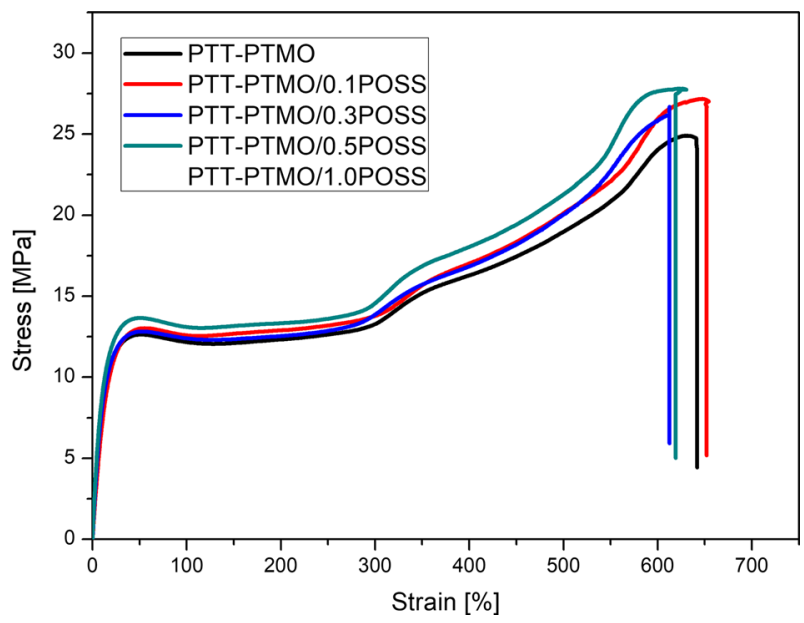

Fig. 1 Representative stress-strain curves for neat PTT-PTMO copolymer and PTT-PTMO/POSS nanocomposites

Table 2 Tensile properties of PTT-PTMO/POSS nanocomposites

\begin{tabular}{llllll}
\hline Sample & $\sigma(100 \%)(\mathrm{MPa})$ & $\sigma_{\mathrm{y}}(\mathrm{MPa})$ & $\varepsilon_{\mathrm{y}}(\%)$ & $\sigma_{\mathrm{b}}(\mathrm{MPa})$ & $\varepsilon_{\mathrm{b}}(\%)$ \\
\hline PTT-PTMO & $11.7 \pm 0.1$ & $12.3 \pm 0.2$ & $36.5 \pm 1.3$ & $23.7 \pm 0.3$ & $625 \pm 7$ \\
PTT-PTMO/0.1 POSS & $12.2 \pm 0.1$ & $12.7 \pm 0.1$ & $48.0 \pm 0.1$ & $23.8 \pm 0.2$ & $642 \pm 14$ \\
PTT-PTMO/0.3 POSS & $12.6 \pm 0.1$ & $12.9 \pm 0.1$ & $49.1 \pm 1.1$ & $27.6 \pm 0.2$ & $652 \pm 14$ \\
PTT-PTMO/0.5 POSS & $12.3 \pm 0.1$ & $12.8 \pm 0.1$ & $48.2 \pm 0.8$ & $29.9 \pm 0.9$ & $612 \pm 17$ \\
PTT-PTMO/1.0 POSS & $13.1 \pm 0.1$ & $13.6 \pm 0.1$ & $47.1 \pm 0.9$ & $28.6 \pm 0.7$ & $618 \pm 41$
\end{tabular}

$\sigma(100 \%)$ stress at strain of $100 \%, \sigma_{y}, \varepsilon_{y}$ yield stress and strain, respectively, $\sigma_{b}, \varepsilon_{b}$ stress and strain at break, respectively

particles accounted for reinforcing agents. Similarly, Zhi et al. [41] in the epoxy/multifunctional POSS nanocomposites and epoxy/ladderlike polyphenylsilsesquioxane blends noticed an improvement in the mechanical properties (better dimensional stability, increase in flexural modulus, and increase in hardness) due to an incorporation of POSS particles. In addition, Verker et al. [42] in polyimide (PI)/ POSS) thin films observed from the typical tensile stress-strain curves a ductile-tobrittle transition, with a maximum elongation and tensile strength at $5 \mathrm{wt} \%$ POSS. Whereas, an increase in the POSS content to $10 \mathrm{wt} \%$ POSS led to the reduction in toughness compared to PI. Further increase in POSS content up to $15 \mathrm{wt} \%$ POSS led to further reduction in toughness, resulting in the lowest tensile strength and elongation at break of $104 \mathrm{MPa}$ and $12 \%$, respectively. The reduction in toughness in PI based nanocomposites containing 10 and $15 \mathrm{wt} \%$ of POSS was probably due to the disruption of the polymer molecular structure [43], which did not occur with the $5 \mathrm{wt} \%$ POSS. The increase in the $5 \mathrm{wt} \%$ POSS-PI toughness indicated on the 
interactions between the PI chains and the POSS particles. This interaction could have been associated with either crazing [44, 45] or chemical cross-linking.

\section{Thermal stability}

The mass loss and its derivative curves for PTT-PTMO-based nanocomposites containing POSS particles in the air and argon atmosphere are presented in Fig. 2. The values of the characteristics temperatures, including the temperatures of 5, 10, and $50 \%$ mass loss $\left(T_{5 \%}, T_{10 \%}\right.$, and $\left.T_{50 \%}\right)$ and the temperatures at a maximum mass loss $\left(T_{\mathrm{DTG}}\right)$ for neat PTT-PTMO copolymer and PTT-PTMO-based nanocomposites are summarized in Table 3. Both mechanisms of thermal and thermo-oxidative degradation of copoly(ether-ester) have been already widely discussed in $[46,47]$. Decomposition process of copoly(ether-ester) begins with the decay of flexible segment PTMO. Oxygen mainly affects the carbon atom located in the $\alpha$ position relative to the ether oxygen atom in ether [46]. Detailed studies have been performed for PBT-PTMO copolymers; however, for the PTT-PTMO, the mechanism is identical, differing only in the decay fragments. The thermal decomposition process of poly(1,4-tetrakismethylene) (PTMO) chains has a radical nature, and in the initial stage of PTMO chain decomposition, the secretion of tetrahydrofuran (THF) aldehydes and low-boiling and volatile alkenes is observed. At the temperature of $200{ }^{\circ} \mathrm{C}$, the thermal oxidation of PTMO segment with releasing volatile substances occurs.

The studies on the effect of POSS content on the thermal decomposition of PTTPTMO nanocomposites proved that in oxidized atmosphere, the thermal degradation process proceeds in two steps and starts at $319{ }^{\circ} \mathrm{C}$ (with $0.1 \mathrm{wt} \%$ of POSS) and at $304{ }^{\circ} \mathrm{C}$ (with $1.0 \mathrm{wt} \%$ of POSS) (Fig. 2a), whereas in an inert atmosphere proceeds in only one step which starts at $362{ }^{\circ} \mathrm{C}$ (with $0.1 \mathrm{wt} \%$ of POSS) and at $358{ }^{\circ} \mathrm{C}$ (with $1.0 \mathrm{wt} \%$ of POSS) (Fig. 2b). The values of 5, 10, and 50\% of mass loss in an oxidizing atmosphere are lower when POSS particles where added to the polymer system. $T_{5 \%}, T_{10 \%}$, and $T_{50 \%}$ of PTT-PTMO block copolymer were determined to be at 346,358 , and $398{ }^{\circ} \mathrm{C}$, respectively. In the case of PTT-PTMO/POSS composites, the thermal degradation temperatures distinctly decreased with the increasing POSS
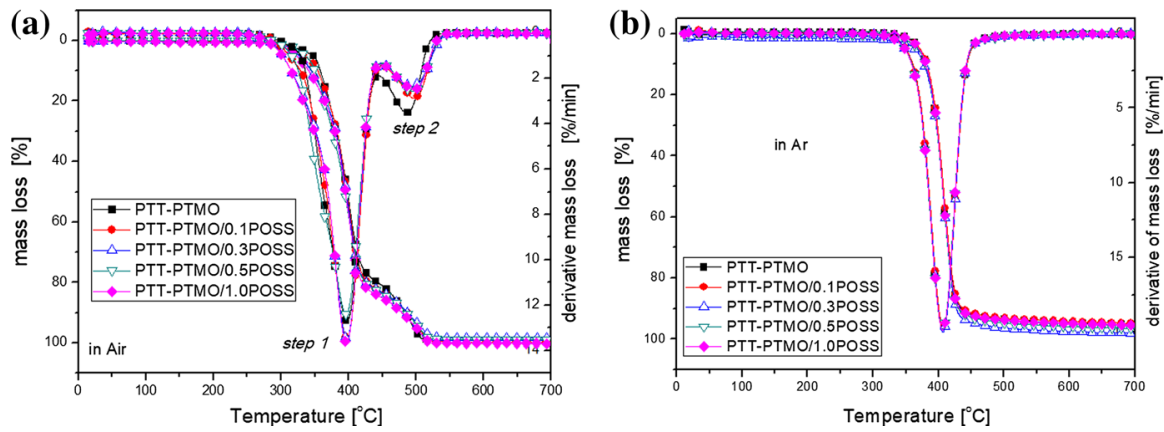

Fig. 2 Mass loss and derivative of mass loss as a function of temperature for PTT-PTMO/POSS nanocomposites in the air (a) and in argon (b) 
Table 3 Temperatures corresponding to 5, 10, and 50\% mass loss, and the temperature at maximum of mass loss rate for the PTT-PTMO/POSS nanocomposites obtained in the air and argon atmosphere

\begin{tabular}{lcclll}
\hline Symbol & $T_{5 \%}\left({ }^{\circ} \mathrm{C}\right)$ & $T_{10 \%}\left({ }^{\circ} \mathrm{C}\right)$ & $T_{50 \%}\left({ }^{\circ} \mathrm{C}\right)$ & $T_{\text {DTG } 1}\left({ }^{\circ} \mathrm{C}\right)$ & $T_{\text {DTG } 2}\left({ }^{\circ} \mathrm{C}\right)$ \\
\hline $\begin{array}{l}\text { Measurement carried out in an oxidizing atmosphere } \\
\text { PTT-PTMO }\end{array}$ & 346 & 358 & 398 & 397 & 487 \\
PTT-PTMO/0.1 POSS & 334 & 354 & 398 & 397 & 497 \\
PTT-PTMO/0.3 POSS & 327 & 345 & 397 & 397 & 497 \\
PTT-PTMO/0.5 POSS & 336 & 350 & 395 & 397 & 498 \\
PTT-PTMO/1.0 POSS & 323 & 341 & 395 & 397 & 499 \\
Measurement carried out in argon & & & & \\
PTT-PTMO & 371 & 381 & 407 & 405 & - \\
PTT-PTMO/0.1 POSS & 372 & 382 & 407 & 405 & - \\
PTT-PTMO/0.3 POSS & 370 & 378 & 406 & 405 & - \\
PTT-PTMO/0.5 POSS & 372 & 380 & 406 & 406 & - \\
PTT-PTMO/1.0 POSS & 370 & 380 & 406 & 406 & - \\
\hline
\end{tabular}

content. For instance, $T_{5 \%}$ of the PTT-PTMO nanocomposite with $0.5 \mathrm{wt} \%$ POSS was $336{ }^{\circ} \mathrm{C}$, which is $10{ }^{\circ} \mathrm{C}$ lower than that of PTT-PTMO copolymer. Moreover, PTT-PTMO/POSS nanocomposites exhibited comparable values of $T_{\mathrm{DTG} 1}$ to the neat PTT-PTMO. However, at the same time, the addition of POSS particles caused a shift of $10-12{ }^{\circ} \mathrm{C}$ toward higher temperatures of the value of the maximum of mass loss rate $\left(T_{\mathrm{DTG} 2}\right)$. In the second step, the pyrolysis of carbonaceous char takes place at higher temperatures (shift of $T_{\mathrm{DTG} 2}$ ) due to the presence of $\mathrm{Si}-\mathrm{O}-\mathrm{Si}$ linkages in char. In turn, in an inert atmosphere, the values of $T_{5 \%}, T_{10 \%}$ and $\mathrm{T}_{50 \%}$, as well as $T_{\mathrm{DTG} 1}$ are comparable or only slightly lower than those observed for neat PTT-PTMO. Thermal degradation profiles of PTT-PTMO nanocomposites in the case of an inert atmosphere displayed that thermal stability of the nanocomposites was not affected by the addition of POSS particles content up to $1.0 \mathrm{wt} \%$. Similarly, Wu et al. [48] confirmed that the incorporation of POSS can enhance the thermal stability of the poly(butylene terephthalate) (PBT)/POSS. They suggested that the existence of the POSS did not significantly alter the degradation mechanism of the matrix polymers. Moreover, in nitrogen, the thermal stability of the nanocomposites was improved with the incorporation of POSS cages. However, there was a turning point of decomposition temperature with the increase amount of POSS. When the POSS content was less than $5 \mathrm{wt} \%$, the decomposition temperature of the nanocomposites increased with the increase of POSS content, whereas when the POSS content was more than $5 \mathrm{wt} \%$, the decomposition temperature began to decrease. In turn, Rashid et al. [49] reported that epoxy-POSS composites sustained higher temperatures prior to decomposition and, thus, had a higher decomposition temperature. This was ascribed to the steric hindrance of the polymer chains due to the presence of bulky POSS side groups. In addition, Zheng et al. [50], who studied the effect of the amount of POSS nanoparticles on the thermal stability of 
polyethylene (PE), confirmed that PE/POSS composites exhibited an improved thermal stability (as suggested by an increase in the onset of decomposition temperature). The increase in the onset of decomposition temperature under nitrogen was attributed to the possible cross-linking between scissioned PE chains and the POSS silicone core. It is also well-mentioning that Huang et al. [51], who studied POSS/polyimide (PI) nanocomposites noted that the thermal stability of POSS-containing composites depended on POSS-polymer surface interactions, the amount of POSS, and cross-linking.

The analysis on the obtained results and the literature review confirms that the addition of POSS particles might improve the thermal stability. However, this improvement is strongly depended on the amount of the nanofillers, the presence of functional groups on its surface, and its distribution throughout the entire volume the polymer matrix. No apparent effect in our case may be due to the low concentration of nanofiller (maximum content of $1 \mathrm{wt} \%$ ).

\section{Dielectric spectroscopy}

One can modify the dielectric properties of the materials by incorporating nanosized fillers, like POSS, into polymeric matrices. Such a modification in dielectric properties of polymer nanocomposites can be ascribed to various factors, i.e., large particle-polymer interfacial area, particle-polymer nanoscopic structure, and change in internal electric field (polarization) due to the presence of nanoparticles [1]. Several studies have already presented the dielectric properties of POSS/ polymer nanocomposites using dielectric spectroscopy (DS) [52-54]. Dielectric spectroscopy (DS) can be very sensitive method for analyzing the effect of polymer crystallization [55]. Therefore, for the neat PTT-PTMO and PTT-PTMO/1.0POSS nanocomposites, the DS measurement has been performed. In Fig. 3a, b, the dielectric loss versus temperature and frequency were plotted for PTT-PTMO copolymer and PTT-PTMO-based nanocomposites. In the temperature range from - 150 to $50{ }^{\circ} \mathrm{C}$ for neat PTT-PTMO copolymer, one can observe the presence of
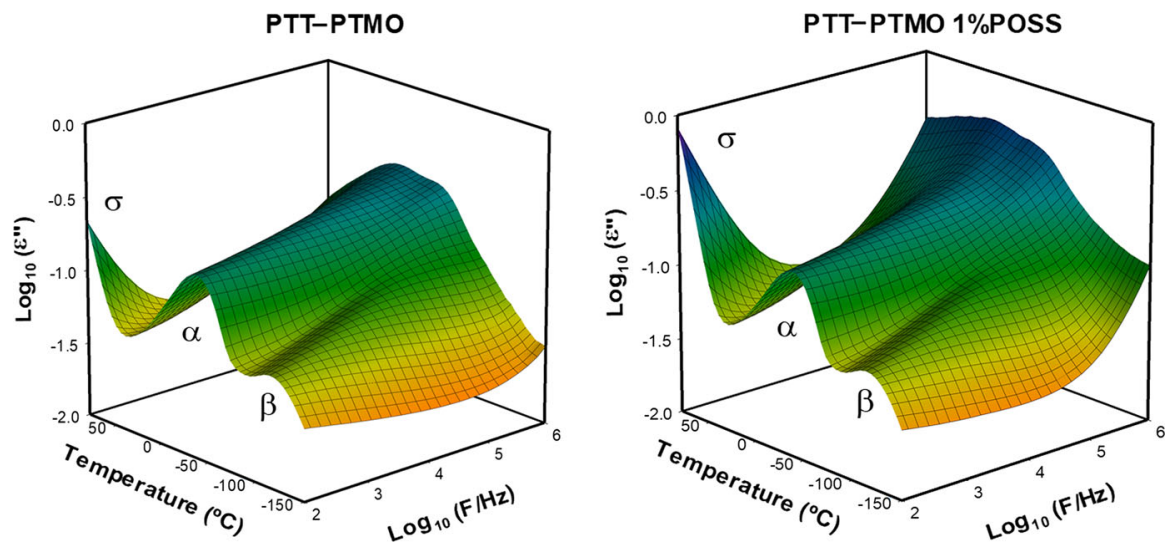

Fig. 3 Dielectric loss as a function of temperature and frequency 
two relaxation peaks: $\beta$ and $\gamma$. For both materials, a secondary relaxation peak $(\beta)$ can be seen between -150 and $-80{ }^{\circ} \mathrm{C}$, which is related to local ether rotation of soft segments. At higher temperatures, for both samples, we only observe a relaxation $(\alpha)$ corresponding to the glass transition temperature. These results are consistent with DSC measurements. No significant differences are observed between matrix and nanocomposite. Above this temperature, for low frequencies, an increase of the dielectric loss (due to interfacial polarization phenomena) can be seen $(\sigma)$. For the $\beta$ relaxation, the time corresponding to the maximum of dielectric loss $\left(\tau_{\max }\right)$ values as a function of the inversed temperature for neat PTT-PTMO block copolymer and PTT-PTMO/POSS nanocomposite is presented in Fig. 4. These samples follow an Arrhenius behavior, and from the slope of the straight line, it is possible to obtain the activation energy $\left(E_{\mathrm{a}}\right)(1)$ :

$$
\tau_{\max }=\tau_{\mathrm{o}} \exp \left(-\frac{E_{\mathrm{a}}}{R T}\right) .
$$

$E_{\text {a }}$ calculated for $\beta$ relaxation process in neat block copolymer and POSS nanocomposite are 35.91 and $32.27 \mathrm{~kJ} / \mathrm{mol}$, respectively. For the nanocomposite, a slight reduction of $E_{\mathrm{a}}$ for the $\beta$-relaxation processes was found. Relating to dielectric constant, $\varepsilon^{\prime}$, it is worth pointing out that the values observed for the nanocomposite are higher than those corresponding to the matrix (Fig. 5). This fact indicates that an increase of the polarization caused by the increment of polymer/nanoadditive interfaces, which would be responsible for the final properties of the material.

In like manner, Raftopoulos et al. [56] studied the series of polyurethanes (PU)/ POSS nanocomposites with broadband dielectric relaxation spectroscopy (DRS). Secondary relaxations remained unaffected by POSS. $T_{\mathrm{g}}$ raised by few degrees and, in consistency of that, segmental dynamics slightly slowed down with an increasing

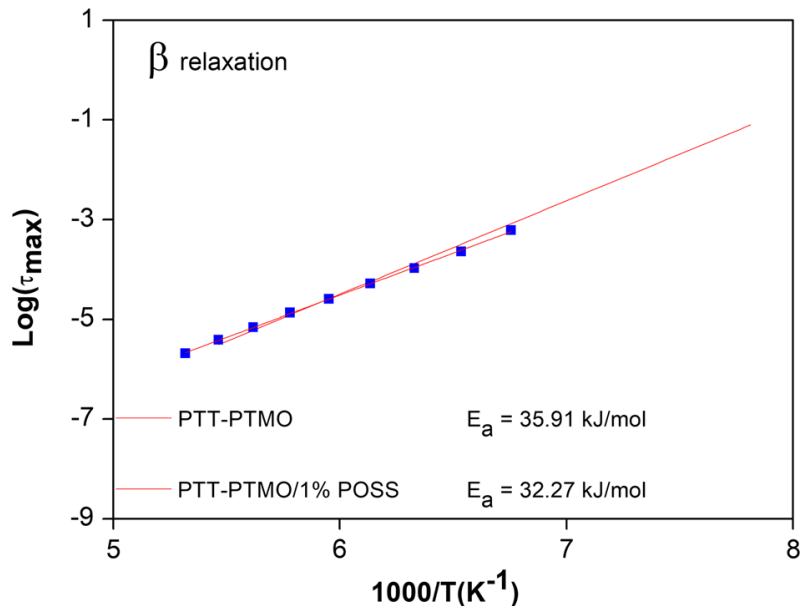

Fig. 4 Dependence of the time of maximum loss of the $\beta$ relaxation as a function of the reciprocal temperature 

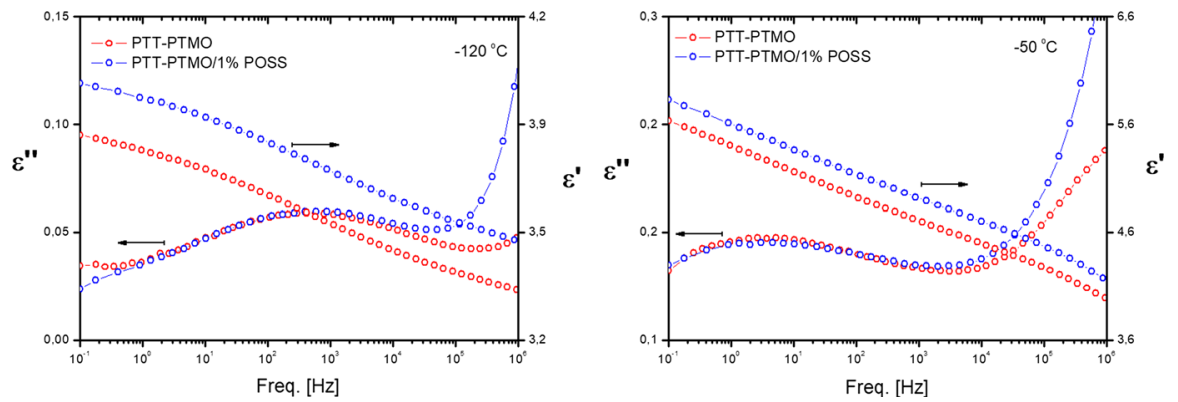

Fig. 5 Dependence of $\varepsilon^{\prime \prime}$ and $\varepsilon^{\prime}$ with frequency, for PTT-PTMO and PTT-PTMO with 1 wt\% POSS, at two temperatures where $\alpha\left(-50{ }^{\circ} \mathrm{C}\right)$ and $\beta\left(-120{ }^{\circ} \mathrm{C}\right)$ relaxations are observed

content of POSS. In addition, the dielectric strength of the segmental relaxation decreased with increasing content of POSS, suggesting that a fraction of polymer was immobilized, making no contribution to the relaxation. In general, incorporation of POSS into polymeric matrices can alter the mobility of polymers adjacent to particles. Thus, the incorporation of POSS particles can alter $T_{\mathrm{g}}$ of the POSScontaining composite material. It can be assumed that larger content of POSS particles would change the glass transition temperature, but in our study, we aimed to improve the thermal stability and mechanical properties at the lowest possible content of POSS. For this reason, neither $T_{\mathrm{g}}$, as measured by DSC (Table 1), nor the associated $\alpha$-relaxation (Fig. 5) exhibits significant variations. The presence of additional functional groups on the surface of POSS could alter $T_{\mathrm{g}}$ of nanocomposites. This was confirmed by $\mathrm{Wu}$ et al. [48], who noticed that POSS macromonomers behaved as joint points for all PBT chains, and thus restricted the free motion of chain segments, leading to the $T_{\mathrm{g}}$ enhancement. It was obvious that more POSS cores meant more limitation to the PBT chains, accounting for the $T_{\mathrm{g}}$ enhancement with the increase of POSS content. In addition, POSS-polymer surface interactions were found to strongly affect $T_{\mathrm{g}}$ [57]. The effect of three different surface functional POSS groups, isobutyl (iBu), cyclopentyl (Cp), and cyclohexyl (Cy), on the linear viscoelastic behavior of PS, revealed that $T_{\mathrm{g}}$ was strongly dependent on surface functional groups of POSS particles [57]. One observed that $\mathrm{iBu}-\mathrm{POSS}$ served as a plasticizer reducing the glass transition, while Cp-POSS increased the glass transition, whereas the PS/Cy-POSS hybrids exhibited intermediate behavior. The variation in $T_{\mathrm{g}}$ in the polymer/POSS nanocomposites found to be a net result of several effects that include free volume fraction, steric barrier, as well as the polymer/POSS segment interactions [57].

\section{Conclusions}

In summary, a series of PTT-PTMO-based nanocomposites have been successfully prepared via in situ polymerization with the functionalized POSS. The structure and thermal properties were characterized in detail. TGA indicated that the addition of POSS particles might improve the thermal stability. However, this improvement is 
strongly depended on the amount of the nanofillers, the presence of functional groups on its surface, and its distribution throughout the entire volume the polymer matrix. No apparent effect in our case was probably be due to the low concentration of nanofiller (maximum content of $1 \mathrm{wt} \%$ ). In turn, tensile tests confirmed that POSS cages may play the role of the reinforcing agents of PTT-PTMO block copolymer. Whereas, an increase in hardness of PTT-PTMO/POSS nanocomposites in comparison with neat PTT-PTMO might have resulted from the influence of POSS particles on the molecular mobility of polymer chains, which is probably due to the interfacial interactions between functional groups on the surface of POSS particles with the polymer matrix. This was in the agreement with the observations made from the dielectric spectroscopy, where for PTT-PTMO/1\%POSS nanocomposite, increase of the $\varepsilon^{\prime}$ in comparison with neat PTT-PTMO copolymer is observed.

Acknowledgements Sandra Paszkiewicz and Daria Pawlikowska would like to thank for financial support from West Pomeranian University of Technology (Dean's grant for young scientists). Authors would like to thank DuPont Tate \& Lyle BioProducts company for providing bio-1,3-propanediol for experimental use.

Open Access This article is distributed under the terms of the Creative Commons Attribution 4.0 International License (http://creativecommons.org/licenses/by/4.0/), which permits unrestricted use, distribution, and reproduction in any medium, provided you give appropriate credit to the original author(s) and the source, provide a link to the Creative Commons license, and indicate if changes were made.

\section{References}

1. Ayandele E, Sarkar P (2012) Polyhedral oligomeric silsesquioxane (POSS)-containing polymer nanocomposites. Nanomaterials 2:445-475. https://doi.org/10.3390/nano2040445

2. Kuo SW, Chang FC (2011) POSS related polymer nanocomposites. Prog Polym Sci 36:1649-1696. https://doi.org/10.1016/j.progpolymsci.2011.05.002

3. Cordes DB, Lickiss PD, Rataboul F (2010) Recent developments in the chemistry of cubic polyhedral oligosilsesquioxanes. Chem Rev 110:2081-2173. https://doi.org/10.1021/cr900201r

4. Shea KJ, Loy DA (2001) Bridged polysilsesquioxanes. Molecular-engineered hybrid organic-inorganic materials. Chem Mater 13:3306-3319. https://doi.org/10.1021/cm011074s

5. Lickiss PD, Rataboul F (2008) Fully condensed polyhedral oligosilsesquioxanes (POSS): from synthesis to application. In: Hill AF, Fink MJ (eds) Advances in organometallic chemistry, vol 57. Academic Press Inc, Oxford, pp 1-116

6. Philips SH, Haddad TS, Tomczak SJ (2004) Developments in nanoscience: polyhedral oligomeric silsesquioxane (POSS)-polymers. Curr Opin Solid State Mater Sci 8:21-29. https://doi.org/10.1016/j. cossms.2004.03.002

7. Camargo PHC, Satyanarayana KG, Wypych F (2009) Nanocomposites: synthesis, structure, properties and new application opportunities. Mater Res 12:1-39. https://doi.org/10.1590/S151614392009000100002

8. Lagashetty A, Venkataraman A (2005) Polymer nanocomposites. Resonance 10:49-57

9. Zhou Z, Cui L, Zhang Y, Yin N (2008) Preparation and properties of POSS grafted polypropylene by reactive blending. Eur Polym J. 44:3057-3066. https://doi.org/10.1016/j.eurpolymj.2008.05.036

10. Chan ER, Striolo A, McCabe C, Cummings PT, Glotzer S (2007) Coarse-grained force field for simulating polymer-tethered silsesquioxane self-assembly in solution. J Chem Phys 127:114102. https://doi.org/10.1063/1.2753493 
11. Zeng K, Zheng S (2007) Nanostructures and surface dewettability of epoxy thermosets containing hepta(3,3,3-trifluoropropyl) polyhedral oligomeric silsesquioxane-capped poly(ethylene oxide). J Phys Chem B. 111:1319-13928. https://doi.org/10.1021/jp075891c

12. Guo Q, Knight PT, Mather PT (2009) Tailored drug release from biodegradable stent coatings based on hybrid polyurethanes. J Controlled Release 137:224-233. https://doi.org/10.1016/j.jconrel.2009. 04.016

13. Liu YL (2012) Developments of highly proton-conductive sulfonated polymers for proton exchange membrane fuel cells. Polym Chem 3:1373-1383. https://doi.org/10.1039/C2PY20106B

14. Madbouly SA, Lendlein A (2010) Shape-memory polymer composites. In: Lendlein A (ed) Shapememory polymers, vol 226. Springer. Berlin, Germany, pp 41-95

15. Choi J, Harcup J, Yee AF, Zhu Q, Laine RM (2001) J Am Chem Soc 123:11420-11430. https://doi. org/10.1021/ja0107201

16. Striolo A, McCabe C, Cummings PT (2005) Thermodynamic and transport properties of polyhedral oligomeric sislesquioxanes in poly(dimethylsiloxane). J Phys Chem B 109:14300-14307. https://doi. org/10.1021/jp045388p

17. Striolo A, McCabe C, Cummings PT (2006) Organic-inorganic telechelic molecules: solution properties from simulations. J Chem Phys 125:104904. https://doi.org/10.1063/1.2348641

18. Balazs A, Emrick T, Russell T (2006) Nanoparticle polymer composites: where two small worlds meet. Science 314:1107-1110. https://doi.org/10.1126/science.1130557

19. Lin Y, Alexandridis P (2002) Temperature-dependent adsorption of Pluronic F127 block copolymers onto carbon black particles dispersed in aqueous media. Langmuir 106:10834-10844. https://doi.org/ $10.1021 / \mathrm{jp} 014221 \mathrm{i}$

20. Lin Y, Smith T, Alexandridis P (2002) Adsorption of a rake-type siloxane surfactant onto carbon black nanoparticles dispersed in aqueous media. Langmuir 18:6147-6158. https://doi.org/10.1021/ la011671t

21. Anderson J, Sknepnek R, Travesset A (2010) Design of polymer nanocomposites in solution by polymer functionalization. Phys Rev E 82:021803. https://doi.org/10.1103/PhysRevE.82.021803

22. McKeen LW (2010) Fatigue and tribological properties of plastics and elastomers, 2nd edn. Elsevier, Oxford, $\mathrm{p} 245$

23. Paszkiewicz S, Pilawka R, Dudziec B, Dutkiewicz M, Marciniec B, Kochmańska A, Jędrzejewski R, Rosłaniec Z (2015) Morphology and phase separation in PTT-block-PTMO nanocomposites containing POSS particles. Eur Polym J 70:37-44. https://doi.org/10.1016/j.eurpolymj.2015.07.004

24. http://www2.dupont.com/Plastics/en_US/pfo/assets/downloads/hytrel/HDG112013.pdf. Accessed 10 Sept 2017

25. Naderi G, Razavi-Nouri M, Taghizadeh E, Lafleur PG, Dubois C (2010) Preparation of thermoplastic elastomer nanocomposites based on polyamide-6/polyepichlorohydrin-co-ethylene oxide. Polym Eng Sci 51:278-284. https://doi.org/10.1002/pen.21824

26. Calleja FJB, Rosłaniec Z (2000) Block copolymers. Marcel Dekker. Inc., New York

27. Adams RK, Hoeschele GK, Witsiepe WK (2004) Thermoplastic polyether-ester elastomers. In: Holden G, Kricheldorf HR, Quirk AP (eds) Thermoplastic elastomers. Hanser, Munich, pp 183-216

28. Szymczyk A, Senderek E, Nastalczyk J, Rosłaniec Z (2008) New multiblock poly(ether-ester)s based on poly(trimethylene terephthalate) as rigid segments. Eur Polym J 44:436-443. https://doi.org/10. 1016/j.eurpolymj.2007.11.005

29. Szymczyk A, Paszkiewisz S, Rosłaniec Z (2013) Influence of intercalated organoclay on the phase structure and physical properties of PTT-PTMO block copolymers. Polym Bull 70:1575-1590. https://doi.org/10.1007/s00289-012-0859-y

30. Paszkiewicz S, Taraghi I, Szymczyk A, Huczko A, Kurcz M, Przybyszewski B, Stanik R, Linares A, Ezquerra TA, Rosłaniec Z (2017) Electrically and thermally conductive thin elastic polymer foils containing SiC nanofibers. Compos Sci Technol 146:20-25. https://doi.org/10.1016/j.compscitech. 2017.04.016

31. Szymczyk A (2012) Poly(trimethylene terephthalate-block-tetramethylene oxide) elastomer/singlewalled carbon nanotubes nanocomposites: synthesis, structure, and properties. J Appl Polym Sci 126:796-807. https://doi.org/10.1002/app.36961

32. Paszkiewicz S, Szymczyk A, Špitalský Z, Mosnáĉek J, Kwiatkowski K, Rosłaniec Z (2014) Structure and properties of nanocomposites based on PTT-block-PTMO copolymer and graphene oxide prepared by in situ polymerization. Eur Polym J 50:69-77. https://doi.org/10.1016/jeurpolymj.2013.10. 031 
33. Paszkiewicz S, Szymczyk A, Pilawka R, Przybyszewski B, Czulak A, Rosłaniec Z (2017) Improved thermal conductivity of poly(trimethylene terephthalate-block-poly(tetramethylene oxide) based nanocomposites containing hybrid single-walled carbon nanotubes/graphene nanoplatelets fillers. Adv Polym Technol 36:236-242. https://doi.org/10.1002/adv.21611

34. Paszkiewicz S, Szymczyk A, Sui XM, Wagner HD, Linares A, Ezquerra TA, Rosłaniec Z (2015) Synergetic effect of single-walled carbon nanotubes (SWCNT) and graphene nanoplatelets (GNP) in electrically conductive PTT-block-PTMO hybrid nanocomposites prepared by in situ polymerization. Compos Sci Technol 118:72-77. https://doi.org/10.1016/j.compscitech.2015.08.011

35. Paszkiewicz S, Taraghi I, Szymczyk A, Piesowicz E, Rosłaniec Z (2017) Nanocomposites based on thermoplastic polyester Elastomers. In: Cankaya N (ed) elastomers. InTech, Rijeka. https://doi.org/ 10.5772/intechopen.68216

36. Mammeri F, Douja N, Bonhomme C, Ribot F, Babonneau Dirè S (2005) Modification and characterization of Si-based nanobuilding blocks to design hybrid oxide-polymer materials. Mater Res Soc Symp Proc 847:363. https://doi.org/10.1557/PROC-847-EE13.26

37. Mammeri F, Bonhomme C, Ribot F, Babonneau F, Dirè S (2009) New monofunctional POSS and its utilization as dewetting additive in methacrylate based free-standing films. Chem Mater 21:4163-4171. https://doi.org/10.1021/cm900339h

38. Cordes DB, Lickiss PD, Rataboul F (2010) Recent developments in the chemistry of cubic polyhedral oligosilsesquioxanes. Chem Rev 110:2081-2173. https://doi.org/10.1021/cr900201r

39. Maciejewski H, Szubert K, Marciniec B (2012) New approach to synthesis of functionalised silsesquioxanes via hydrosilylation. Catal Commun 24:1-4. https://doi.org/10.1016/j.catcom.2012. 03.011

40. Marciniec B, Dutkiewicz M, Maciejewski H, Kubicki M (2008) New, effective method of synthesis and structural characterization of octakis(3-chloropropyl)octasilsesquioxane. Organometallics 27:793-794. https://doi.org/10.1021/om700962x

41. Li GZ, Wang L, Tohiani H, Daulton TL, Koyama K, Pittman CU (2001) Viscoelastic and mechanical properties of epoxy/multifunctional polyhedral oligomeric silsesquioxane nanocomposites and epoxy/ladderlike polyphenylsilsesquioxane blends. Macromolecules 34:8686-8693. https://doi.org/ $10.1021 / \mathrm{ma0} 11117 \mathrm{q}$

42. Verker R, Grossman E, Gouzman I, Eliaz N (2009) TriSilanolPhenyl POSS-polyimide nanocomposites: structure-properties relationship. Compos Sci Technol 69:2178-2184. https://doi.org/10. 1016/j.compscitech.2009.06.001

43. Zhao Y, Schiraldi DA (2005) Thermal and mechanical properties of polyhedral oligomeric silsesquioxane (POSS)/polycarbonate composites. Polymer 46:11640-11647. https://doi.org/10.1016/ j.polymer.2005.09.070

44. Jordan J, Jacob KI, Tannenbaum R, Sharaf MA, Jasiuk I (2005) Experimental trends in polymer nanocomposites—a review. Mater Sci Technol 393:1-11. https://doi.org/10.1016/j.msea.2004.09.044

45. Ash BJ, Rogers DF, Wiegand CJ, Schadler LS, Siegel RW, Benicewicz BC, Apple R (2002) Mechanical properties of $\mathrm{Al}_{2} \mathrm{O}_{3}$ /polymethylmethacrylate nanocomposites. Polym Compos 23:1014-1025. https://doi.org/10.1002/pc.10497

46. Szymczyk A, Rosłaniec Z (2006) Degradacja i stabilizacja termoplastycznych elastomerów. Polimery 51:627-642

47. Rosłaniec Z (2005) Polyester thermoplastic elastomers: synthesis, properties, and some applications. In: Fakirov RZ (ed) Handbook of condensation thermoplastic elastomers. Wiley-VCH, Germany, pp 77-106

48. Wu F, Xie T, Yang G (2010) Characterization of PBT/POSS nanocomposites prepared by in situ polymerization of cyclic poly(butylene terephthalate/9 initiated by functionalized POSS. J Polym Sci Part B Polym Phys 48:1853-1859. https://doi.org/10.1002/polb.22060

49. Rashid ESA, Ariffin K, Kooi CC, Akil HM (2009) Preparation and properties of POSS/epoxy composites for electronic packaging applications. Mater Des 30:1-8. https://doi.org/10.1016/j. matdes.2008.04.065

50. Zheng L, Farris RJ, Coughlin EB (2001) Synthesis of polyethylene hybrid copolymers containing polyhedral oligomeric silsesquioxane prepared with ring-opening metathesis copolymerization. J Polym Sci Part A Polym Chem 39:2920-2928. https://doi.org/10.1002/pola.1272

51. Huang JC, He CB, Xiao Y, Mya KY, Dai J, Siow YP (2003) Polyimide/POSS nanocomposites: interfacial interaction, thermal properties and mechanical properties. Polymer 44:4491-4499. https:// doi.org/10.1016/S0032-3861(03)00434-8 
52. Hao N, Böhning M, Schönhals A (2007) Dielectric properties of nanocomposites based on polystyrene and polyhedral oligomeric phenethyl-silsesquioxanes. Macromolecules 40:9672-9679. https://doi.org/10.1021/ma071777g

53. Hao N, Böhning M, Goerign A, Schönhals A (2007) Nanocomposites of polyhedral oligomeric phenethylsilsesquioxanes and poly(bisphenol A carbonate) as investigated by dielectric spectroscopy. Macromolecules 40:2955-2964. https://doi.org/10.1021/ma070036c

54. Klocek J, Henkel K, Kolanek K, Zschech E, Schmeißer D (2012) Spectroscopic and capacitancevoltage characterization of thin aminopropylmethoxysilane films doped with copper phthalocyanine, tris(dimethylvinylsilyloxy)-POSS and fullerene cages. Appl Surf Sci 258:4213-4221. https://doi.org/ 10.1016/j.apsusc.2011.12.004

55. Sanz A, Nogales A, Ezquerra TA, Lotti N, Munari A, Funari SS (2006) Order and segmental mobility during polymer crystallization: poly(butylene isophthalate). Polymer 47:1281-1290. https://doi.org/ 10.1016/j.polymer.2005.12.047

56. Raftopoulos KN, Pandis C, Apekis L, Pissis P, Jankowski B, Pielichowski K, Jaczewska J (2010) Polyurethane-POSS hybrids: molecular dynamics studies. Polymer 51:709-718. https://doi.org/10. 1016/j.polymer.2009.11.067

57. Wu J, Haddad TS, Mather PT (2009) Vertex group effects in entangled polystyrene-polyhedral oligosilsesquioxane (POSS) copolymers. Macromolecules 42:1142-1152. https://doi.org/10.1021/ ma8024267 